\title{
Alteration of retinal layers in healthy subjects over 60 years of age until nonagenarians
}

This article was published in the following Dove Press journal:

Clinical Ophthalmology

16 August 2017

Number of times this article has been viewed

\author{
Lebriz Altay' \\ Cheryl Jahn' \\ Mücella Arikan Yorgun' \\ Albert Caramoy' \\ Tina Schick' \\ Carel B Hoyng ${ }^{2}$ \\ Anneke I den Hollander ${ }^{2}$ \\ Sascha Fauser ${ }^{\prime}$ \\ 'Department of Ophthalmology, \\ University Hospital of Cologne, \\ Cologne, Germany; ${ }^{2}$ Department of \\ Ophthalmology, Radboud University \\ Nijmegen Medical Centre, Nijmegen, \\ the Netherlands
}

Purpose: To assess alterations of retinal layers in healthy subjects over 60 years old.

Methods: Retinal layers of 160 healthy subjects (aged 60-100 years) without any retinal pathology were imaged using spectral domain optical coherence tomography. Mean thickness of retinal nerve fiber layer, ganglion cell/inner plexiform layer (GCLIPL), inner nuclear layer, outer plexiform layer/outer nuclear layer, photoreceptor complex (PR) and retinal thickness (RT) were measured in a $3.45 \mathrm{~mm}$ grid. Correlations between age and layers were estimated and linear regression equations were calculated. Different age-groups (60-69, 70-79, 80-89 years and nonagenarians, each group with 40 participants) were compared.

Results: Significant age-thickness correlations were observed for GCLIPL $(P<0.001$, $r=-0.394)$, PR $(P<0.001, r=-0.370)$ and RT $(P<0.001, r=-0.290)$. A comparison between age groups 60-69 years and nonagenarians showed no significant thickness alteration of retinal nerve fiber layer $(21.80 \pm 2.18 \mu \mathrm{m}$ vs $22.82 \pm 2.97 \mu \mathrm{m}, P=0.163)$, inner nuclear layer $(37.23 \pm 3.02 \mu \mathrm{m}$ vs $36.01 \pm 3.24 \mu \mathrm{m}, P=0.07)$ and outer plexiform layer/outer nuclear layer $(104.95 \pm 6.56 \mu \mathrm{m}$ vs $104.23 \pm 7.59 \mu \mathrm{m}, P=0.567)$, while GCLIPL $(83.35 \pm 7.35 \mu \mathrm{m}$ vs $74.38 \pm 9.09 \mu \mathrm{m})$, PR $(83.03 \pm 3.31 \mu \mathrm{m}$ vs $79.34 \pm 2.09 \mu \mathrm{m})$ and RT $(330.64 \pm 12.63 \mu \mathrm{m}$ vs $316.83 \pm 18.35 \mu \mathrm{m})$ showed a significant decrease $(P<0.001$ for all $)$.

Conclusion: Our study provides normative data of alterations of retinal layers for persons aged 60 years to nonagenarians and indicates a continuous decrease of RT, PR, and GCLIPL. This data may be useful for clinical trials investigating macular diseases in older patients.

Keywords: nonagenarians, SDOCT, retinal thickness, very elderly, photoreceptor, healthy

\section{Introduction}

Spectral domain optical coherence tomography (SDOCT) is a cornerstone of posterior segment imaging of the eye, providing non-invasive and reproducible measurements of different retinal layers. It is widely used in clinical practice but also in clinical trials for retinal diseases such as age-related macular degeneration (AMD) and diabetic macular edema. For all these applications, it is important to understand the effect of aging on the various retinal layers. So far, normative SDOCT data is limited to subjects aged approximately 70 years. ${ }^{1}$ However, due to increased life expectancy, it will be necessary to provide normative data for clinical routine and clinical trials for the elderly.

The focus of this study was to assess alterations in SDOCT of individual retinal layers in the eyes of healthy subjects aged from 60 to 100 years.

\section{Methods}

One hundred and sixty eyes from 160 healthy subjects aged between 60 to 100 years without AMD and without other retinal or optic disc pathology (high myopia $\geq-6.00$ diopters, myopic fundus degeneration, diabetic retinopathy/maculopathy, uveitis,
Correspondence: Lebriz Altay

Department of Ophthalmology,

University Hospital of Cologne, Kerpener

Str. 62, 50924 Cologne, Germany

Tel +4922I 4783525

Fax +49 22I 4783526

Email lebriz.altay@uk-koeln.com
Clinical Ophthalmology 2017:| | |499-1503

1499 
macular hole, epiretinal membrane, vitreomacular traction, retinal vascular disease, glaucoma, etc.) were included in this study (four age groups: 60-69, 70-79, 80-89 years and nonagenarians, each with 40 participants). All subjects were healthy control participants from The European Genetic Database (www.eugenda.org) who fulfilled the inclusion criteria and were randomized before the start of the study.

Grading of retinal images included stereo fundus photographies (stereo technique is performed with slightly shifting of the camera and sequential images of the same subject can be obtained for a stereo-pair) and SDOCTs (Spectralis HRA, Heidelberg Engineering, Heidelberg, Germany). The study was performed in accordance with the tenets of the Declaration of Helsinki, and the Medical Research Involving Human Subjects Act (WMO) and was approved by the local ethics committee of the University Hospitals in Cologne and Nijmegen. Written informed consent was obtained from all participants.

The nonagenarians (90-100 year olds) could have only small drusen or pigmentary abnormalities with not more than nine small drusen in the Early Treatment of Diabetic Retinopathy Study grid, while participants aged $<90$ years were not permitted to have any drusen or any other qualitative abnormalities in the whole SDOCT volume scan of both eyes.

Calculations of mean thickness values of standardized SDOCT scans (protocol of 37 B-scans) were performed in a $3.45 \mathrm{~mm}$ grid that was manually centered on the fovea. Automatic delineation was performed by Spectralis software (Heidelberg Eye Explorer Software Version 2014, Version 1.9.10.0, Heidelberg Engineering $\mathrm{GmbH}$, Germany) and misalignments were manually corrected. The calculations were performed for retinal nerve fiber layer (RNFL), ganglion cell layer/inner plexiform layer (GCLIPL), inner nuclear layer (INL), outer plexiform layer/outer nuclear layer (OPLONL) and for photoreceptor (PR) complex (external limiting membrane until Bruch's membrane) (Figure 1). The combined thickness of all retinal layers was referred to as retinal thickness (RT). These layers were chosen because of their good visibility on SDOCT, as reported in a previous study. ${ }^{2}$

Due to previously reported moderate-to-high concordance in retinal layer thicknesses between the right and the left eye, ${ }^{2,3}$ we subsequently decided to use the right eye for segmentation in all eyes, except in 15 eyes where poor image quality precluded the use of right eye images.

To avoid gender influence, groups included equal numbers of male and female subjects (20 males and 20 females in each age-group), only the nonagenarian group consisted

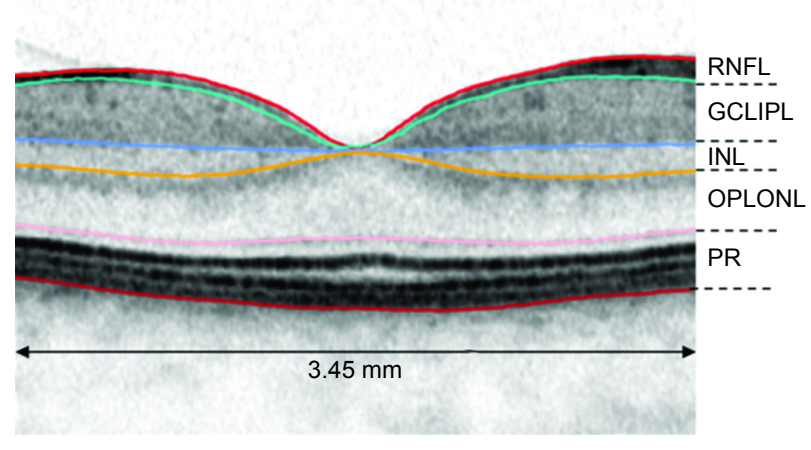

Figure I Schematic illustration of $3.45 \mathrm{~mm}$ diameter grid and chosen retinal layers for segmentation.

Abbreviatons: RNFL, retinal nerve fiber layer; GCLIPL, ganglion cell/inner plexiform layer; INL, inner nuclear layer; OPLONL, outer plexiform layer/outer nuclear layer; PR, photoreceptor complex.

of 12 males and 28 females due to a shortage of male nonagenarians.

\section{Statistical analysis}

All analyses were conducted using SPSS software version 22.0 (IBM Corporation, Armonk, NY, USA). Linear regression analysis was performed for all patients. Age-thickness correlations were performed using Spearman-Rho coefficient. Nonparametric Mann-Whitney $U$-test was used for thickness comparison of different retinal layers between 60-69 years age group vs $\geq 90$ years age group. $P$-values $<0.05$ were accepted as significant.

\section{Results}

In this study, a total of 160 healthy eyes (145 right eyes, 15 left eyes) were evaluated. Mean age of participants was $79.3 \pm 10.9$ years (range $60-100$ years). Demographics and mean thickness values of each evaluated layer are outlined in Table 1 for the different age groups.

Thickness of retinal layer and age correlated significantly for GCLIPL $(P<0.001, r=-0.394)$, PR $(P<0.001, r=-0.370)$ and RT $(P<0.001, r=-0.290)$ but not for RNFL, INL, and OPLONL. Regression equations for these layers with each scatterplot are shown in Figure 2.

Comparison of subjects aged 60-69 years to nonagenarians showed no significant thickness alterations for RNFL (mean $21.80 \pm 2.18 \mu \mathrm{m}$ vs $22.82 \pm 2.97 \mu \mathrm{m}, P=0.163$ ), INL (mean 37.23 $\pm 3.02 \mu \mathrm{m}$ vs $36.01 \pm 3.24 \mu \mathrm{m}, P=0.07$ ) and OPLONL (mean $104.95 \pm 6.56 \mu \mathrm{m}$ vs $104.23 \pm 7.59 \mu \mathrm{m}$, $P=0.567)$, where alteration of GCLIPL $(83.35 \pm 7.35 \mu \mathrm{m}$ vs $74.38 \pm 9.09 \mu \mathrm{m}), \operatorname{PR}(83.03 \pm 3.31 \mu \mathrm{m}$ vs $79.34 \pm 2.09 \mu \mathrm{m})$ and RT $(330.64 \pm 12.63 \mu \mathrm{m}$ vs $316.83 \pm 18.35 \mu \mathrm{m})$ were significant $(P<0.001$ for all) (Table 1). 
Table I Demographics, mean \pm SD of each evaluated layer for each age-group

\begin{tabular}{|c|c|c|c|c|}
\hline & $60-69$ years & 70-79 years & 80-89 years & $\geq 90$ years \\
\hline $\mathrm{N}$ (patients) & 40 & 40 & 40 & 40 \\
\hline Age, years (mean $\pm S D$ ) & $64.95 \pm 3.02$ & $75.40 \pm 3.04$ & $83.33 \pm 2.64$ & $93.40 \pm 2.79$ \\
\hline \multicolumn{5}{|l|}{ Gender } \\
\hline Female (n) & 20 & 20 & 20 & 12 \\
\hline Male (n) & 20 & 20 & 20 & 28 \\
\hline \multicolumn{5}{|l|}{ Retinal layers } \\
\hline RNFL, $\mu \mathrm{m}($ mean $\pm \mathrm{SD})$ & $21.80 \pm 2.18$ & $22.62 \pm 2.25$ & $22.18 \pm 2.23$ & $22.82 \pm 2.97$ \\
\hline GCLIPL, $\mu \mathrm{m}($ mean $\pm \mathrm{SD})$ & $83.35 \pm 7.35$ & $78.54 \pm 6.67$ & $74.52 \pm 9.67$ & $74.38 \pm 9.09$ \\
\hline $\mathrm{INL}, \mu \mathrm{m}($ mean $\pm \mathrm{SD})$ & $37.23 \pm 3.02$ & $36.72 \pm 4.24$ & $36.43 \pm 3.54$ & $36.01 \pm 3.24$ \\
\hline OPLONL, $\mu \mathrm{m}($ mean $\pm S D)$ & $104.95 \pm 6.56$ & $103.66 \pm 6.94$ & $105.04 \pm 7.95$ & $104.23 \pm 7.59$ \\
\hline $\mathrm{PR}, \mu \mathrm{m}($ mean $\pm \mathrm{SD})$ & $83.03 \pm 3.31$ & $81.45 \pm 2.89$ & $81.24 \pm 3.59$ & $79.34 \pm 2.09$ \\
\hline $\mathrm{RT}, \mu \mathrm{m}($ mean $\pm \mathrm{SD})$ & $330.64 \pm 12.63$ & $323.19 \pm|3.7|$ & $321.22 \pm 14.69$ & $316.83 \pm 18.35$ \\
\hline
\end{tabular}

Abbreviations: GCLIPL, ganglion cell/inner plexiform layer; INL, inner nuclear layer; OPLONL, outer plexiform-outer nuclear layer; PR, photoreceptor complex; RNFL, retinal nerve fiber layer; RT, retinal thickness; SD, standard deviation.

\section{Discussion}

In this study, we provided normative data of thickness of different retinal layers measured with SDOCT in healthy subjects aged 60 to 100 years.

Previous studies report an age-dependent reduction of macular RNFL thickness within middle-age persons. ${ }^{4-8}$ However macular RNFL in SDOCT in elderly has not been investigated. In our study, we observed that macular RNFL did not alter after the sixth decade, whereas GCLIPL decreased significantly with increasing age. In concordance, histological studies investigating postmortem human donor eyes also reported a decrease of GCL with increasing age. ${ }^{9}$ Along with this finding, a highly significant cell density decrease of GCL from 20-40 year olds and a slower rate of GCL loss in the following decades was reported. ${ }^{9}$ However, with the SDOCT, GCL cannot reliably be distinguished from the INL layer, therefore a one-to one comparison with histological methods is very difficult.

In this study, we observed a continuous age-dependent decrease of macular retinal thickness. Our results may partly explain the controversial results of several previously published studies; while some studies reported no association of macular thickness with age in healthy eyes, ${ }^{10,11}$ others report a decrease of retinal thickness and volume with increasing age. ${ }^{3,5,12-15}$

In agreement with previous studies, ${ }^{4}$ we found no association of OPLONL thickness alteration with age, although, a reorganization of cells in OPLONL during normal aging cannot be excluded. ${ }^{4,16}$

From all evaluated layers, PR-complex seemed to have the most significant alterations after the age of 80 years. This is partly in concordance with previous macular electroretinogram reports of healthy elderly individuals, that showed a significant age-related decrease of amplitudes that is possibly related to decreased recovery of pigment regeneration in the elderly. ${ }^{17}$ Also, studies that investigated histological sections of human donor eyes reported a photoreceptor and retinal pigment epithelium (RPE) loss with increasing age, and an elevated RPE lipofuscin accumulation over years with the highest values between $73-88$ years. ${ }^{18}$
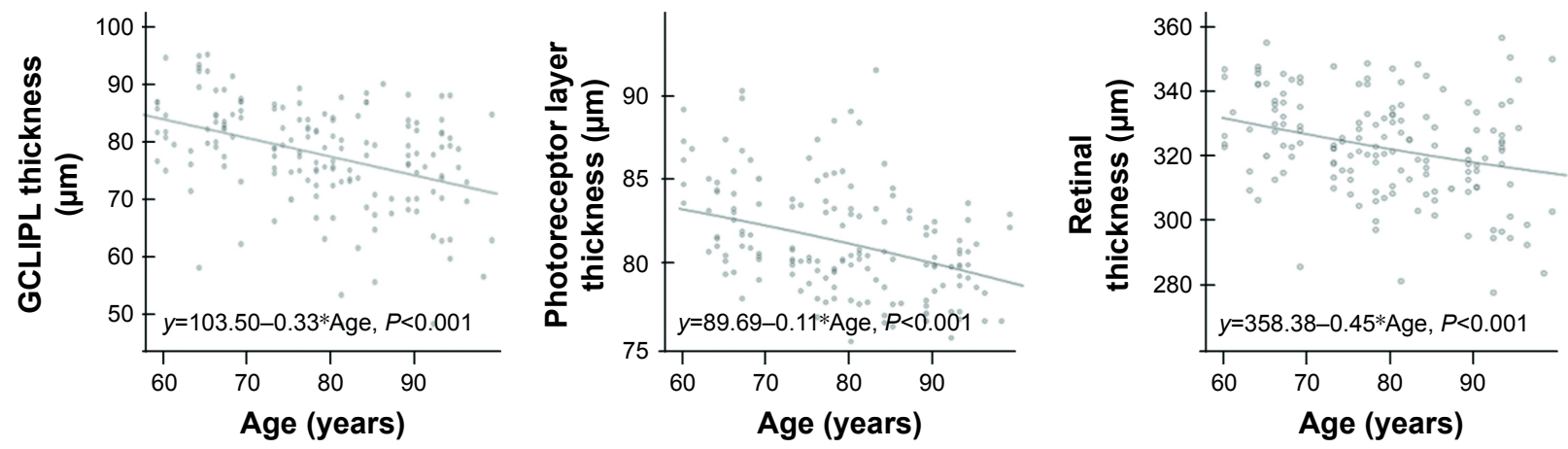

Figure 2 Regression equations for age-related retinal thickness changes in subjects aged $60-100$ years.

Note: GCLIPL, photoreceptor layer and retinal thickness showed significant age-related decrease $(P<0.00 \mathrm{I})$. Abbreviaton: GCLIPL, ganglion cell layer/inner plexiform layer. 
Our study included a large nonagenarian group, who primarily came from a small area in Germany. The recruitment of this special cohort of nonagenarians, who were able to come to attend and comprehend the study's procedures, caused an unavoidable selection bias of the "healthy and mobile" in our study. However, as a consequence of this selection bias, the number of nonagenarians with Alzheimer Disease, dementia or large cerebral infarction, which may affect RNFL thickness, ${ }^{19,20}$ was reduced to a minimum. Another limitation is that RNFL thickness changes should be monitored ideally with additional SDOCT scan around optic nerve head..$^{5}$ Also, thickness changes of all retinal layers can be measured in a 1, 3, and $6 \mathrm{~mm}$ diameter grid, although there is a high concordance in measured mean macular thickness in the central areas by the shorter $(3.45 \mathrm{~mm})$ and the longer $(6 \mathrm{~mm})$ scan length mapping protocols. ${ }^{21}$ A further limitation in our study was using neither a longitudinal nor epidemiological design.

Our study also has several strengths. Concerning our purpose, no studies were found to include an age group of $\geq 90$ years. As there is a rising life expectancy, it is important for future clinical trials to introduce a new age-category of very old patients with corresponding controls. Our study included a large group of nonagenarians with a maximum age of 100 years. Nonagenarian participants were carefully chosen and showed neither AMD nor other macular or optic disc co-pathologies in fundus photographies and in SDOCT. All other subjects except nonagenarians were randomly chosen from a large group of healthy participants (without macular or optic disc pathology) of The European Genetic Database (count $>600$ ).

In summary, in this study we intended to provide normative SDOCT data of different retinal layers using SDOCT from 60 year olds to nonagenarians. As there is a growing number of highly aged persons due to rising life expectancy, our data may be useful for clinical trials investigating the macular diseases for an upcoming age class in society.

\section{Disclosure}

The authors report no conflicts of interest in this work.

\section{References}

1. Myers CE, Klein BE, Meuer SM, et al. Retinal thickness measured by spectral-domain optical coherence tomography in eyes without retinal abnormalities: the Beaver Dam Eye Study. Am J Ophthalmol. 2015;159(3):445.e1-456.e1.

2. Caramoy A, Droege KM, Kirchhof B, Fauser S. Retinal layers measurements in healthy eyes and in eyes receiving silicone oil-based endotamponade. Acta Ophthalmol. 2014;92(4):e292-e297.
3. Caramoy A, Foerster J, Allakhiarova E, et al. Spectral-domain optical coherence tomography in subjects over 60 years of age, and its implications for designing clinical trials. Br J Ophthalmol. 2012;96(10): 1325-1330.

4. Ooto S, Hangai M, Tomidokoro A, et al. Effects of age, sex, and axial length on the three-dimensional profile of normal macular layer structures. Invest Ophthalmol Vis Sci. 2011;52(12):8769-8779.

5. Demirkaya N, van Dijk HW, van Schuppen SM, et al. Effect of age on individual retinal layer thickness in normal eyes as measured with spectral-domain optical coherence tomography. Invest Ophthalmol Vis Sci. 2013;54(7):4934-4940.

6. Rougier MB, Korobelnik JF, Malet F, et al. Retinal nerve fibre layer thickness measured with SD-OCT in a population-based study of French elderly subjects: the Alienor study. Acta Ophthalmol. 2015; 93(6):539-545.

7. Alasil T, Wang K, Keane PA, et al. Analysis of normal retinal nerve fiber layer thickness by age, sex, and race using spectral domain optical coherence tomography. J Glaucoma. 2013;22(7):532-541.

8. Leung CK, Yu M, Weinreb RN, et al. Retinal nerve fiber layer imaging with spectral-domain optical coherence tomography: a prospective analysis of age-related loss. Ophthalmology. 2012;119(4):731-737.

9. Gao H, Hollyfield JG. Aging of the human retina. Differential loss of neurons and retinal pigment epithelial cells. Invest Ophthalmol Vis Sci. 1992;33(1):1-17.

10. Adhi M, Aziz S, Muhammad K, Adhi MI. Macular thickness by age and gender in healthy eyes using spectral domain optical coherence tomography. PLoS One. 2012;7(5):e37638.

11. Wong AC, Chan CW, Hui SP. Relationship of gender, body mass index, and axial length with central retinal thickness using optical coherence tomography. Eye (Lond). 2005;19(3):292-297.

12. Alamouti B, Funk J. Retinal thickness decreases with age: an OCT study. Bri J Ophthalmol. 2003;87(7):899-901.

13. Song WK, Lee SC, Lee ES, Kim CY, Kim SS. Macular thickness variations with sex, age, and axial length in healthy subjects: a spectral domain-optical coherence tomography study. Invest Ophthalmol Vis Sci. 2010;51(8):3913-3918.

14. Eriksson U, Alm A. Macular thickness decreases with age in normal eyes: a study on the macular thickness map protocol in the Stratus OCT. B J Ophthal. 2009;93(11):1448-1452.

15. Rao HL, Kumar AU, Babu JG, Kumar A, Senthil S, Garudadri CS. Predictors of normal optic nerve head, retinal nerve fiber layer, and macular parameters measured by spectral domain optical coherence tomography. Invest Ophthalmol Vis Sci. 2011;52(2):1103-1110.

16. Eliasieh K, Liets LC, Chalupa LM. Cellular reorganization in the human retina during normal aging. Invest Ophthalmol Vis Sci. 2007; 48(6):2824-2830.

17. Messenio D, Marano G, Gerosa S, Iannelli F, Biganzoli EM. The influence of age on the recovery of the ERG photostress test. Doc Ophthalmol. 2013;126(2):87-97.

18. Dorey CK, Wu G, Ebenstein D, Garsd A, Weiter JJ. Cell loss in the aging retina. Relationship to lipofuscin accumulation and macular degeneration. Invest Ophthalmol Vis Sci. 1989;30(8):1691-1699.

19. Moschos MM, Markopoulos I, Chatziralli I, et al. Structural and functional impairment of the retina and optic nerve in Alzheimer's disease. Curr Alzheimer Res. 2012;9(7):782-788.

20. Park HY, Park YG, Cho AH, Park CK. Transneuronal retrograde degeneration of the retinal ganglion cells in patients with cerebral infarction. Ophthalmology. 2013;120(6):1292-1299.

21. Wexler A, Sand T, Elsas TB. Macular thickness measurements in healthy Norwegian volunteers: an optical coherence tomography study. BMC Ophthalmol. 2010;10:13 
Clinical Ophthalmology

\section{Publish your work in this journal}

Clinical Ophthalmology is an international, peer-reviewed journal covering all subspecialties within ophthalmology. Key topics include: Optometry; Visual science; Pharmacology and drug therapy in eye diseases; Basic Sciences; Primary and Secondary eye care; Patien Safety and Quality of Care Improvements. This journal is indexed on

PubMed Central and CAS, and is the official journal of The Society of Clinical Ophthalmology (SCO). The manuscript management system is completely online and includes a very quick and fair peer-review system, which is all easy to use. Visit http://www.dovepress.com/ testimonials.php to read real quotes from published authors. 